\title{
Executive Functions Correlated with Body Mass Index in Overweight Middle-Aged Women
}

\author{
Silvia Solís-Ortiz ${ }^{*}$, Mayra Gutiérrez-Muñoz², Lisette Morado-Crespo', \\ Silvia Aurora Trejo-Bahena ${ }^{1}$, Linaloe Kala ${ }^{3}$ \\ ${ }^{1}$ Departamento de Ciencias Médicas, División de Ciencias de la Salud, Campus León, Universidad de \\ Guanajuato, Guanajuato, México \\ ${ }^{2}$ Facultad de Psicología, Universidad Autónoma de Nuevo León, Monterrey, México \\ ${ }^{3}$ Departamento de Medicina y Nutrición, División de Ciencias de la Salud, Universidad de Guanajuato, \\ Guanajuato, México \\ Email: "silviasolis17@gmail.com
}

Received 22 February 2016; accepted 27 March 2016; published 30 March 2016

Copyright (C) 2016 by authors and Scientific Research Publishing Inc.

This work is licensed under the Creative Commons Attribution International License (CC BY). http://creativecommons.org/licenses/by/4.0/

c) (i) Open Access

\begin{abstract}
The impacts of excess Body mass index (BMI) on physical health are well known and widely studied, but little is known about the consequences of being overweight or obese on cognitive function. The aim of this study was to correlate the BMI with executive functions in overweight middleaged women. Seventy overweight middle-aged women between 48 and 64 years of age who are otherwise healthy participated in the study. Demographic and anthropometric variables were evaluated. Four standard neuropsychological tests were applied to assess executive functions, sustained attention, selective attention, and verbal fluency. The mean BMI of the participants was 29.35 and was negatively correlated with categories reached $(r=-0.41, p=0.007)$ and positively correlated with the number of errors $(r=0.43, p=0.005)$ of executive function test. Scores of other neuropsychological tests applied showed no correlation with BMI. These findings suggest that BMI impacts the executive functions in overweight women who do not present any signs of disease.
\end{abstract}

\section{Keywords}

Cognition, Executive Functions, Body Mass Index, Overweight, Middle-Aged

${ }^{*}$ Corresponding author.

How to cite this paper: Solís-Ortiz, S., Gutiérrez-Muñoz, M., Morado-Crespo, L., Trejo-Bahena, S. A., \& Kala, L. (2016). Executive Functions Correlated with Body Mass Index in Overweight Middle-Aged Women. Psychology, 7, $410-417$. 


\section{Introduction}

Excess body weight is currently recognized as one of the most serious public health problems in the world, given its magnitude, rapid growth, and its adverse effect because it significantly increases the risk of chronic degenerative diseases (World Health Organization, 2013). In Mexico, the prevalence of being overweight has tripled, particularly among the adult population. Approximately $73 \%$ of the adult population in Mexico has a Body mass index (BMI) greater than $25 \mathrm{~kg} / \mathrm{m}^{2}$, three-quarters of women over 20 (73\%) are overweight, and $61.9 \%$ have a waist circumference greater than $80 \mathrm{~cm}$, which is classified as high risk (Barguera, Campos-Nonato, HernándezBarrera, \& Pedroza, 2012). According to the World Health Organization (2010), the BMI is calculated by dividing weight in kilograms by the square of height in meters $\left(\mathrm{kg} / \mathrm{m}^{2}\right)$. The BMI is a simple indication of the ratio between weight and height that is commonly used to identify overweight and obese adult individuals and populations. The WHO defines being overweight as having a BMI equal to or greater than 25, and obese when the BMI is over 30, which implies the gravest consequences for health. High BMI is an important risk factor for cardiovascular disease, diabetes, hypertension, locomotive syndrome, and some cancers (World Health Organization, 2006).

Although the impact of a high BMI on the body of excess is well known and widely studied (Bhurosy \& Jeewon, 2014; Moges, Amare, Fantahumand, \& Kassu, 2014; Olaiz, Rivera, \& Shamah, 2006), and similarly its impacts on health (Zera, McGirr, \& Oken, 2011), little is known about the consequences of being overweight or obese on cognitive function (Yesavage et al., 2014). The diverse studies that have linked BMI to cognitive function observe that obesity in old age is associated with lower cognitive scores (Sabia, Kivimaki, Shipley, Marmot, \& Singh-Manoux, 2009; Dahl Aslan, Starr, Pattie, \& Deary, 2014), but the association between these variables in aging is not yet fully understood. It has also been observed that a high BMI at around 40 years of age precedes a generally lower cognitive ability and cognitive decline in men and women (Dahl et al., 2010). Being either underweight, overweight, or obese have been identified as risk factors for dementia in old age (García-Ptacek, Faxen-Irving, Cermáková, Eriksdotter, \& Religa, 2014; Anstey, Cherbuin, Budge, \& Young, 2011; Gorospe \& Dave, 2007; Gustafson, 2006).

Although most studies establish a relationship between obesity and cognition as risk factors for developing cognitive impairment in different ages and populations, little is known about how the BMI is associated with prefrontal cortex functions in middle-aged women who do not present any other disease. The aim of this study is to correlate BMI with scores of neurocognitive tests measuring executive functions, sustained attention, selective attention, and verbal fluency in middle-aged women.

\section{Method}

\subsection{Participants}

A total of 70 healthy postmenopausal women with a median age of 53 years (age range 48 - 64), with more than a year of amenorrhea without hysterectomy, apparently healthy, right-handed, with minimum primary education, without hormone replacement therapy and without diabetes, hypertension, epilepsy, sclerosis, or alcoholism, who were also not under any drug treatment affecting the central nervous system, with no signs of dementia, participated in a correlational and cross-sectional study. The characteristics of participants such as age, height, weight, education level, and Body mass index were obtained. The research was approved by the Ethics Committee of the Department of Medical Sciences of the University of Guanajuato in accordance with the Declaration of Helsinki (World Medical Association Declaration of Helsinki, 1964) for research on human beings. Each participant had signed a letter of informed consent before the study session began.

\subsection{Neuropsychological Evaluation Instruments}

Four standard neuropsychological tests that measure prefrontal functions (Phillips, 1997) were used to evaluate the correlation with BMI. Each test was administered during a session and was distributed randomly. Neuropsychological tests are described below according to the skills they represent.

\subsubsection{Executive Functions}

The Wisconsin Card Sorting Test (WCST) (Heaton, 1981) was used to evaluate executive functions of the frontal cortex. The performance of the WCST produces physiological activation in a network of regions including 
the dorsolateral prefrontal cortex, the inferior parietal lobule, and the posterior portion of the inferior temporal cortex (Berman et al., 1995). The WCST is an abstract reasoning and problem solving test that involves the use of working memory to form a cognitive set and apply a conceptual strategy but also that necessitates maintenance and then shifting of the set when appropriate. The stimuli were shown on a screen facing the subjects. The WCST requires subjects to discover the principle under which a deck of cards must be sorted. The standard material consists of cards bearing geometric figures that vary in color (red, green, blue, or yellow), form (triangle, star, cross, or circle) and number (1, 2, 3 or 4 items). Four reference cards are aligned in front of the subject throughout the test. Another deck of cards serves as response cards. The subject is instructed to place each response card in front of 1 of the 4 reference cards, wherever she thinks it should go. After each response, she is told whether the response was "right" or "wrong" but not where the card should have gone. The subject's goal is to obtain as many "right" responses as possible. Initially, cards must be sorted according to color. When performance is successful, the sorting rule is changed, from color to form or number; the subject must recognize the change and discover the new correct rule. We analyzed the following results provided by the WCST in a computerized version: 1) the number of categories completed, refer to effectiveness of measured cognitive function; 2) the number of correct responses (trials), taking into account the ability to reach successful or unsuccessful outcomes; 3 ) perseverative errors refer to the number of errors committed by the subject by pursuing an criterion which has received the information that is not valid; 4) errors refer to the number of incorrect answers.

\subsubsection{Selective Attention}

A computerized version of the Stroop test was used to examine selective attention ability (Stroop, 1935). Performance of this test activates the frontal and cingulate cortices (Swick \& Jovanovic, 2002). This test entails multiple cognitive processes including selective attention, response inhibition, interference control, and response speed. The test requires that subjects rapidly shift the perceptual set when viewing the names of colors that appear in matching or non-matching colors. The test consists of a sequence of words that denote the colors green, blue and red and that are displayed in the same colors on the screen. The subjects were instructed to perform the task in two trials. In the first trial, the subject should ignore the text color and press the $\leftarrow$ button if the GREEN word appears, the $\downarrow$ button for the BLUE word, and the $\rightarrow$ button for the RED word. In the second trial, the subject should ignore the meanings of the word and press the same buttons according to text color. Reaction time, number of correct responses, number of no responses and number of errors were computed.

\subsubsection{Sustained Attention}

A computerized version of the Continuous Performance Test (CPT) was used to examine the ability to sustain attention (Rosvold, Mirsky, Sarason, Bransome, \& Beck, 1956). Performance of CPT activates the right frontal and parietal lobes (Manly \& Robertson, 1997). The sustained attention test consists of 150 alphabet letters displayed continuously in a random sequence, one at a time, for 50 milliseconds on a video screen. The inter-trial interval ranged randomly from 5 to 7 seconds. The subjects were instructed to perform the test with two different levels of difficulty. In the first level, the letter "S" pattern was selected as the target stimulus, and the subject was asked to press the "enter" button on the keyboard as soon as possible each time the target stimulus was perceived. In the second level, this instruction was maintained, and the subject was asked to press the "enter" button only when the target stimulus was preceded by a specified item, the letter " $\mathrm{A}$ ". Reaction time, omissions, errors and correct responses were computed.

\subsubsection{Verbal Fluency}

The Word Fluency Test (Benton, Hamsher, Varney, \& Spreen, 1983) was used to evaluate the spontaneous generation of words according to an initial given letter. This test reflects function in the left frontal lobes (Parks et al., 1988). The word production test consisted of asking subjects to write as many words as they could that begin with the alphabet letters F, L, and M, excluding proper nouns, numbers, and the same word with a different suffix, in $1 \mathrm{~min}$. The score was the sum of three 1 min trials with different letters.

\subsection{Data Analysis}

Levene's test was applied to test the normal distribution of the variables prior to the application of the statistical analysis: 1) descriptive statistics were used for the description of the variables of the participants' characteristics, 
2) a Spearman correlation was used to correlate the neuropsychological test scores against BMI. Differences were considered significant at $p<0.05$.

\section{Results}

\subsection{Characteristics of the Participants}

Table 1 describes the characteristics of women participating in the study. The median age was 53 years, average education length of 9 years, weight $69 \mathrm{~kg}$, height $1.56 \mathrm{~m}$, and BMI 29.35 .

\subsection{Correlation}

Table 2 describes the correlation between BMI and neuropsychological test scores. Scores of the neuropsychological test of sustained attention, selective attention and verbal fluency showed no correlation with BMI. These results demonstrate that there is not sufficient evidence to support the conclusion of a linear correlation. Scores of the Wisconsin Card Sorting Test showed significant correlations with BMI. The Body mass index was negatively correlated with categories reached $(r=-0.41, p=0.007)$. The scatterplot in Figure 1 depict a pattern of decreasing values of number of categories reached correspond to increasing values of BMI. The Body mass index was positively correlated with the number of errors $(r=0.43, p=0.005)$. The scatterplot in Figure 2 depict a pattern of increasing values of number of errors correspond to increasing values of BMI.

Table 1. Characteristics of the participants.

\begin{tabular}{cc}
\hline & Median (range) \\
\hline Age (years) & $53(48-64)$ \\
Education & $9(6-15)$ \\
Size $(\mathrm{m})$ & $156(146-164)$ \\
Weight $(\mathrm{kg})$ & $69(65-74)$ \\
Body mass index $\left(\mathrm{kg} / \mathrm{m}^{2}\right)$ & $29.35(23.50-38.44)$ \\
\hline
\end{tabular}

Table 2. Correlation between Body mass index and neuropsychological test scores.

\begin{tabular}{|c|c|c|}
\hline Neuropsychological tests & BMI & $p$ \\
\hline \multicolumn{3}{|l|}{ Sustained attention } \\
\hline Correct responses & -0.27 & 0.08 \\
\hline Errors & 0.25 & 0.12 \\
\hline Omission & 0.10 & 0.28 \\
\hline Reaction time & -0.18 & 0.55 \\
\hline \multicolumn{3}{|l|}{ Selective attention } \\
\hline Correct responses & -0.13 & 0.43 \\
\hline Errors & 0.20 & 0.22 \\
\hline Reaction time & -0.11 & 0.52 \\
\hline Verbal fluency & 0.12 & 0.25 \\
\hline \multicolumn{3}{|l|}{ Wisconsin card sorting test } \\
\hline Number of categories reached & -0.41 & $0.007^{*}$ \\
\hline Number of errors & 0.43 & $0.005^{*}$ \\
\hline Perseverative errors & 0.10 & 0.55 \\
\hline
\end{tabular}




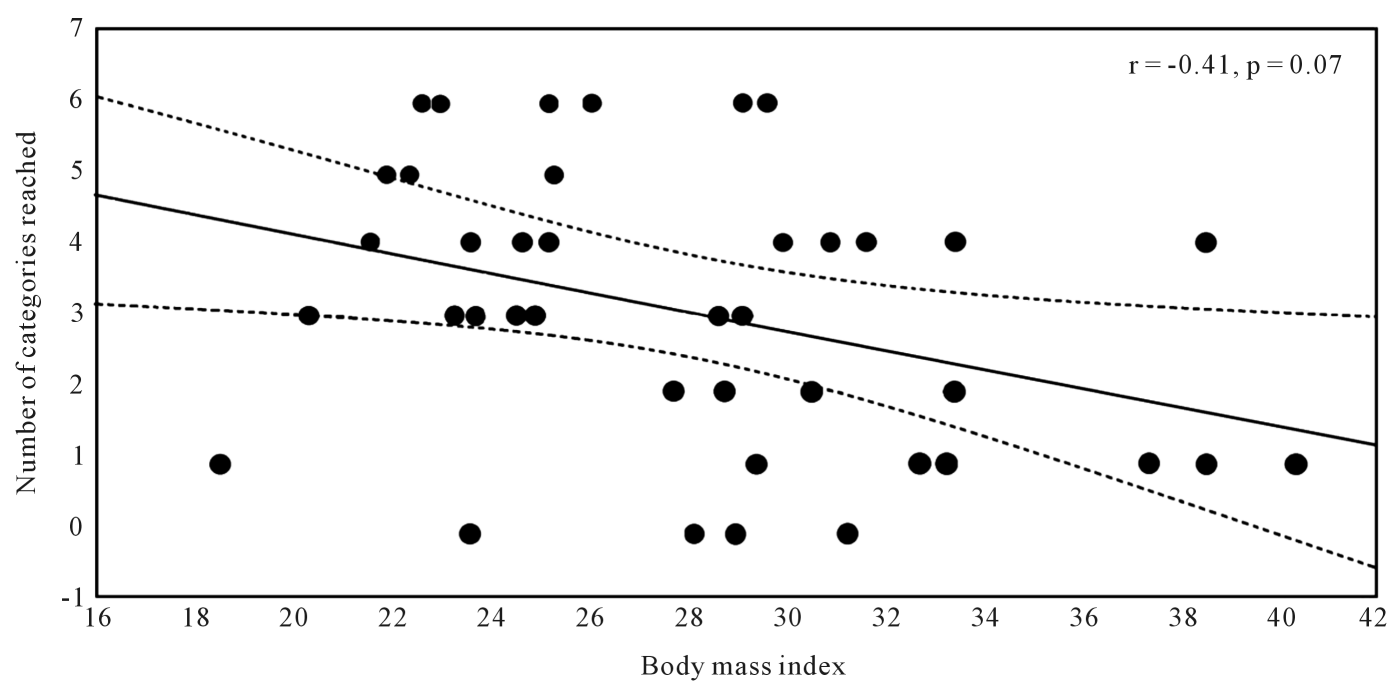

Figure 1. This figure shows the correlation between the number of categories reached in the Wisconsin card sorting test and the Body mass index.

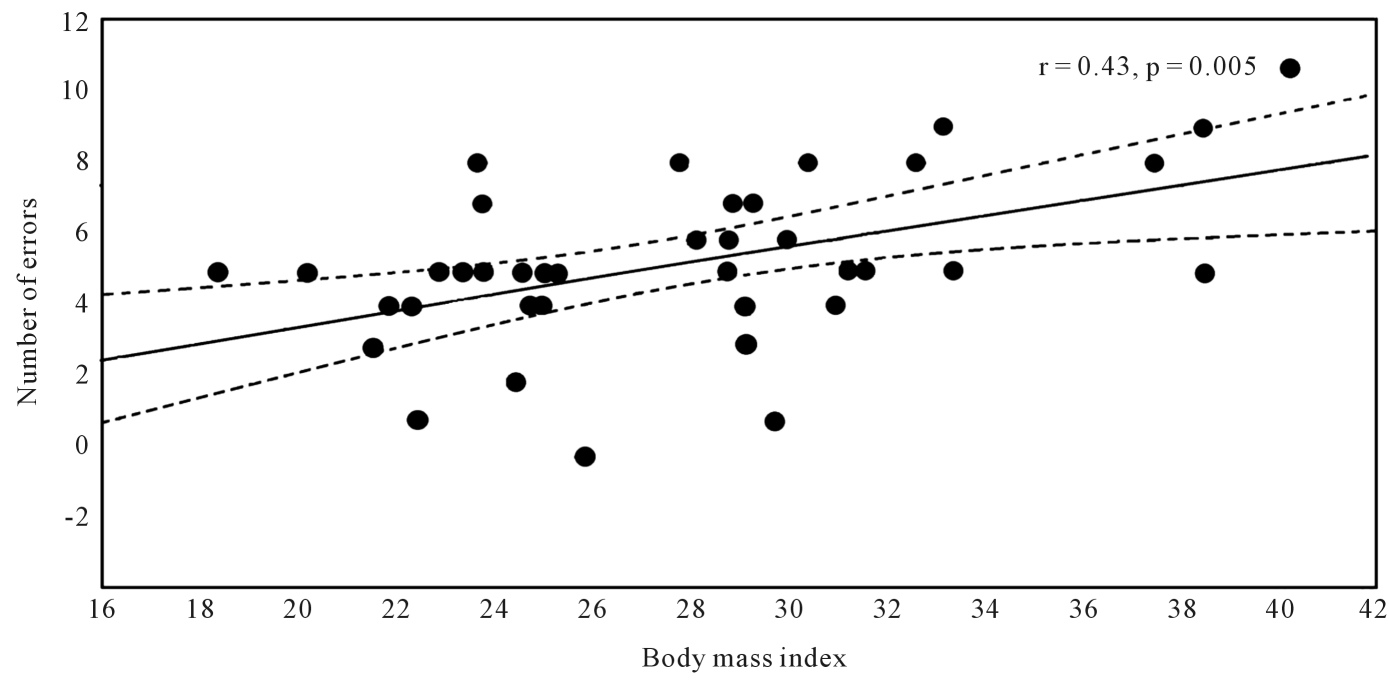

Figure 2. This figure shows the correlation between the number of errors made in the Wisconsin card sorting test and Body mass index.

\section{Discussion}

This study found significant correlations between BMI and some executive functions in middle-aged women who are overweight, suggesting the relationship between height and weight impact the prefrontal cognitive functions. Although rates of correlation between two variables does not indicate causality, the correlations indicate that as the BMI increases, the number of errors increases, and the number of categories achieved during the test that measures executive functions (WCST), suggesting that BMI has an impact on executive functions. Interestingly, we found no correlations with the other functions of attention and verbal fluency evaluated. Some studies have reported an influence of BMI on cognition (Singh-Manoux et al., 2012). A prospective longitudinal study over 26 years based on a middle-aged and elderly sample population found that BMI in midlife was associated with a risk of incident dementia assessed by cognitive and emotional influence on decision-making, numeracy and attention (Tolppanen, Ngandu, Kåreholt, Laatikainen, Rusanen, \& Kivipelto, 2014). A prospective meta-analysis found that a high risk for Alzheimer's diseases, vascular dementia, and any other dementia is associated with an overweight BMI, compared to a healthy BMI in middle age (Anstey, Cherbuin, Budge, \& Young, 2011). Another longitudinal study among people aged 11 - 90 years of age found weak associations be- 
tween BMI, age, and cognitive function, however low intelligence at the age of 11 years predicted obesity at age 79 (Dahl Aslan, Starr, Pattie, \& Deary, 2014).

The WCST test applied in this study involves the assessment of skills related to abstract reasoning, the use of cognitive strategies for problem-solving, planning, working memory, organization and goal-directed behavior (Heaton, 1981). All these functions are known as executive functions attributed to the prefrontal cortex (Nauta, 1971; Stuss, Benson, Clermont, Della Malva, Kaplan, \& Weir, 1986; Goldman-Rakic, 1987; Fuster, Bauer, \& Jervey, 1985; Petrides, 1991; Damasio \& Tranel, 1993). This study observed that BMI was correlated with executive functions in a group of middle-aged women who do not present any disease. It has been reported that these executive functions are particularly affected in vascular dementia (Desmond, 2004), a type of dementia that affects the vascular system, being overweight is a major risk factor for vascular diseases (Kopelman, 2000) and can influence executive functions through the vascular pathway.

There are several hypotheses about the causes of the relationship between BMI and cognitive functions. One such suggests a direct action of adiposity in neuronal tissue through pro-inflammatory mediators produced by adipocytes and endocrine messengers that respond to food ingestion (Funahashi, Yada, Suzuki, \& Shioda, 2003; Harvey, 2003; Bray, 2014). Adipose tissue is known as a source of pro-inflammatory cytokines in obese humans and in animal models due to receptor insensitivity to leptin. Most obese people have an altered adipose tissue function caused by the interaction of genetic and environmental factors, which lead to hypertrophy, hypoxia, and a variety of inflammatory processes in the adipose tissue. Visceral fat accumulation may be considered a consequence of a dysfunction of adipose tissue, characterized by changes in cell function, increased lipid storage and secretion of pro-inflammatory molecules such as cytokines, and inflammatory and pro-coagulant peptides (Blüher, 2009; Gutiérrez, Puglisi, \& Hasty, 2009). One study found that levels of interleukins $1 \beta$ (IL1ß) correlated with adiposity and cognitive impairment (Erion et al., 2014). Inflammation, particularly chronic low-grade inflammation seems to affect several brain functions, from the early development of the brain to the development of neurodegenerative and psychiatric diseases, associated with cognitive deficits and dementia (Wärnberg, Gomez-Martinez, Romeo, Diaz, \& Marcos, 2009). Another hypothesis focuses on the factors involved in arteriosclerosis and vascular factors involved in dementia. Cardiovascular diseases are associated with obesity, Alzheimer, and vascular dementia (Decarli, 2004).

\section{Conclusion}

In conclusion, the results found in this study indicate a relationship between BMI with executive functions in overweight women who are otherwise healthy. These correlations were of great interest since the female participants showed no metabolic disorders such as diabetes, hypertension, high fat nor high cholesterol, they were only overweight. Therefore, we must pay attention to diet and exercise for weight loss and its impact on cognition.

There are some limitations that must be addressed in the present study. This study was conducted in a specific sample of the middle-aged women with overweight. The study did not include middle-aged women with underweight and with and diagnosis of other diseases like early dementia, which must be included in future approaches. Another limitation of the study was that it only included a group of women between 48 and 65 years. Others studies must include individuals of different ages and gender. Prospective and longitudinal designs that include treatments to improve cognitive function and weight reduction may contribute to improve understanding of cognitive decline and obesity.

\section{Acknowledgements}

The research was partially supported by the University of Guanajuato. The English edition was made by the DAIP of the University of Guanajuato. The authors acknowledge the support of Psychologist Eduardo Vazquez.

\section{Contribution of Author}

Silvia Solis-Ortiz conceived, designed, and conducted the study, analyzed the data and wrote the manuscript. Mayra Gutierrez-Muñoz, Lisette Morado-Crespo, Silvia Aurora Trejo-Bahena, Linaloe Kala ran the study. All authors read and approved the final manuscript. 


\section{Conflict of Interests}

The authors declare no conflicts of interest.

\section{References}

Anstey, K. J., Cherbuin, N., Budge, M., \& Young, J. (2011). Body Mass Index in Midlife and Late-Life as a Risk Factor for Dementia: A Meta-Analysis of Prospective Studies. Obesity Review, 12, e426-e437. http://dx.doi.org/10.1111/j.1467-789X.2010.00825.x

Barguera, S., Campos-Nonato, I., Hernández-Barrera, L., Pedroza, A. (2012). Sobrepeso y obesidad en adultos. In Encuesta Nacional de Salud y Nutrición 2012 (pp. 180-186). Cuernavaca México: Instituto Nacional de Salud Pública

Benton, A., Hamsher, K. D., Varney, N., \& Spreen, O. (1983). Contribution to Neuropsychological Assessment. New York: Oxford University Press.

Berman, K. F., Ostrem, J. L., Randolph, C., Gold, J., Goldberg, T. E., Coppola, R., Carson, R. E., Herscovitch, P., \& Weinberger, D. R. (1995). Physiological Activation of a Cortical Network During Performance of the Wisconsin Card Sorting Test: A Positron Emission Tomography Study. Neuropsychologia, 33, 1027-1046. http://dx.doi.org/10.1016/0028-3932(95)00035-2

Bhurosy, T., \& Jeewon, R. (2014). Overweight and Obesity Epidemic in Developing Countries: A Problem with Diet, Physical Activity, or Socioeconomic Status? Scientific World Journal, 2014, Article ID: 964236. http://dx.doi.org/10.1155/2014/964236

Blüher, M. (2009). Adipose Tissue Dysfunction in Obesity. Experimental and Clinical Endocrinology \& Diabetes, 117, 241250. http://dx.doi.org/10.1055/s-0029-1192044

Bray, N. (2014). Neuroimmunology: Obesity Inflames Memory Circuits. Nature Reviews Neuroscience, $15,204$. http://dx.doi.org/10.1038/nrn3713

Dahl Aslan, A. K., Starr, J. M., Pattie, A., \& Deary, I. (2014). Cognitive Consequences of Overweight and Obesity in the Ninth Decade of Life? Age Ageing, pii: afu108.

Dahl, A., Hassing, L. B., Fransson, E., Berg, S., Gatz, M., Reynolds, C. A., \& Pedersen, N. L. (2010). Being Overweight in Midlife Is Associated with Lower Cognitive Ability and Steeper Cognitive Decline in Late life. The Journals of Gerontology, 65, 57-62. http://dx.doi.org/10.1093/gerona/glp035

Decarli, C. (2004). Vascular Factors in Dementia: An Overview. The Journal of the Neurological Sciences, 226, 19-23. http://dx.doi.org/10.1016/j.jns.2004.09.005

Damasio, A. R., \& Tranel, D. (1993). Nouns and Verbs Are Retrieved with Differently Distributed Neural Systems. Proceeding of the National Academy of Science of the United State of America, 90, 4957-4960. http://dx.doi.org/10.1073/pnas.90.11.4957

Desmond, D. W. (2004). The Neuropsychology of Vascular Cognitive Impairment: Is There a Specific Cognitive Deficit? The Journal of the Neurological Sciences, 226, 3-7. http://dx.doi.org/10.1016/j.jns.2004.09.002

Erion, J. R., Wosiski-Kuhn, M., Dey, A., Hao, S., Davis, C. L., Pollock, N. K., \& Stranahan, A. M. (2014). Obesity Elicits Interleukin 1-Mediated Deficits in Hippocampal Synaptic Plasticity. The Journal Neuroscience, 34, 2618-2631. http://dx.doi.org/10.1523/JNEUROSCI.4200-13.2014

Funahashi, H., Yada, T., Suzuki, R., \& Shioda, S. (2003). Distribution, Function, and Properties of Leptin Receptors in the Brain. International Review of Cytology, 224, 1-27. http://dx.doi.org/10.1016/S0074-7696(05)24001-9

Fuster, J. M., Bauer, R. H., \& Jervey, J. P. (1985). Functional Interactions between Inferotemporal and Prefrontal Cortex in a Cognitive Task. Brain Research, 330, 299-307. http://dx.doi.org/10.1016/0006-8993(85)90689-4

García-Ptacek, S., Faxén-Irving, G., Cermáková, P., Eriksdotter, M., \& Religa D. (2014). Body Mass Index in Dementia. European Journal of Clinical Nutrition, 68, 1204-1209. http://dx.doi.org/10.1038/ejcn.2014.199

Goldman-Rakic, P. S. (1987). Development of Cortical Circuitry and Cognitive Function. Child Development, 58, 601-22. http://dx.doi.org/10.2307/1130201

Gorospe, E. C., \& Dave, J. K. (2007). The Risk of Dementia with Increased Body Mass Index. Age Aging, 36, $23-29$. http://dx.doi.org/10.1093/ageing/afl123

Gustafson, D. (2006). Adiposity Indices Dementia. The Lancet Neurology, 5, 713-720. http://dx.doi.org/10.1016/S1474-4422(06)70526-9

Gutiérrez, D. A., Puglisi, M. J., \& Hasty, A. H. (2009). Impact of Increased Adipose Tissue Mass on Inflammation, Insulin, Resistance, and Dyslipidemia. Current Diabetes Reports, 9, 26-32. http://dx.doi.org/10.1007/s11892-009-0006-9

Harvey, J. (2003). Novel Actions of Leptin in the Hippocampus. Annals of Medicine, 35, 197-206. 
http://dx.doi.org/10.1080/07853890310008251

Heaton, R. K. (1981). Manual for the Wisconsin Card Sorting Test Odessa. Lutz, FL: Psychological Assessment Resources.

Kopelman, P. G. (2000). Obesity as a Medical Problem. Nature, 404, 635-643.

Manly, T., \& Robertson, I. H. (1997). Sustained Attention and the Frontal Lobes. In P. Rabbitt (Ed.), Methodology of Frontal and Executive Function (pp. 135-153). East Sussex: Psychology Press.

Moges, B., Amare, B., Fantahun, B., \& Kassu, A. (2014). High Prevalence of Overweight, Obesity, and Hypertension with Increased Risk to Cardiovascular Disorders among Adults in Northwest Ethiopia: A Cross Sectional Study. BMC Cardiovascular Disorders, 14, 155. http://dx.doi.org/10.1186/1471-2261-14-155

Nauta, W. J. (1971). The Problem of the Frontal Lobe: A Reinterpretation. Journal of Psychiatry Research, 8, 167-187. http://dx.doi.org/10.1016/0022-3956(71)90017-3

Olaiz, G., Rivera, J., \& Shamah, T. (2006). Encuesta Nacional de Salud y Nutrición (pp. 97-99). Cuernavaca: Instituto Nacional de Salud Pública.

Parks, R. W., Loewenstein, D. A., Dodrill, K. L., Barker, W. W., Yoshii, F., Chang, J. Y., Emran, A., Apicella, A., Sheramata, W. A., \& Duara, R. (1988) Cerebral Metabolic Effects of a Verbal Fluency Test: A PET Scan Study. Journal of Clinical and Experimental Neuropsychology, 10, 565-575. http://dx.doi.org/10.1080/01688638808402795

Petrides, M. (1991). Functional Specialization within the Dorsolateral Frontal Cortex for Serial Order Memory. Proceedings of the Royal Society B. Biological Sciences, 246, 299-306. http://dx.doi.org/10.1098/rspb.1991.0158

Phillips, L. H. (1997). Do Frontal Test Measure Executive Function? Issues of Assessment and Evidence from Fluency Test. In P. Rabbitt (Ed.), Methodology of Frontal and Executive Function (pp. 191-213). East Sussex: Psychology Press.

Rosvold, H., Mirsky, A., Sarason, I., Bransome, E. D., \& Beck, L. H. (1956). A Continuous Performance Test of Brain Damage. Journal of Consulting and Clinical Psychology, 20, 343-350. http://dx.doi.org/10.1037/h0043220

Sabia, S., Kivimaki, M., Shipley, M., Marmot, M., \& Singh-Manoux, A. (2009). Body Mass Index over the Adult Life Course and Cognition in Lat Midlife: The Whitehall II Cohort Study. The American Journal of Clinical Nutrition, 89, 601-607. http://dx.doi.org/10.3945/ajcn.2008.26482

Singh-Manoux, A., Czernichow, S., Elbaz, A., Dugravot, A., Sabia, S., Hagger-Johnson, G., Kaffashian, S., Zins, M., Brunner, E. J., Nabi, H., \& Kivimäki, M. (2012). Obesity Phenotypes in Midlife and Cognition in Early Old Age: The Whitehall II Cohort Study. Neurology, 79, 755-762. http://dx.doi.org/10.1212/WNL.0b013e3182661f63

Stroop, J. R. (1935). Studies of Interference in Serial Verbal Reactions. The Journal of Experimental Psychology, 18, 643662. http://dx.doi.org/10.1037/h0054651

Stuss, D. T., Benson, D. F., Clermont, R., Della Malva, C. L., Kaplan, E. F., \& Weir, W. S. (1986). Language Functioning after Bilateral Prefrontal Leukotomy. Brain and Language, 28, 66-70. http://dx.doi.org/10.1016/0093-934X(86)90091-X

Swick, D., \& Jovanovic, J. (2002). Anterior Cingulate Cortex and the Stroop Task: Neuropsychological Evidence for Topographic Specificity. Neuropsychologia, 40, 1240-1253. http://dx.doi.org/10.1016/S0028-3932(01)00226-3

Tolppanen, A. M., Ngandu, T., Kåreholt, I., Laatikainen, T., Rusanen, M., Soininen, H., \& Kivipelto, M. (2014). Midlife and Late-Life Body Mass Index and Late-Life Dementia: Results from a Prospective Population-Based Cohort. Journal of Alzheimer's Disease, 38, 201-209.

Wärnberg, J., Gomez-Martinez, S., Romeo, J., Diaz, L. G., \& Marcos, A. (2009). Nutrition, Inflammation and Cognitive Function. Annals of the New York Academy of Sciences, 1153, 164-175. http://dx.doi.org/10.1111/j.1749-6632.2008.03985.x

World Health Organization (2006). Obesity and Overweight. Fact Sheet No. 311. http://www.world.who.int/mediacentre/factsheets/fs311

World Health Organization (2010). Obesity. http://www.who.int/topics/obesity

World Health Organization (2013). Obesity and Overweight Fact Sheet.

World Medical Association Declaration of Helsinki (1964).

Yesavage, J. A., Kinoshita, L. M., Noda, A., Lazzeroni, L. C., Fairchild, J. K., Taylor, J., Kulick, D., Friedman, L., Cheng, J., Zeitzer, J. M., \& O’Hara, R. (2014). Effects of Body Mass Index-Related Disorders on Cognition: Preliminary Results. Diabetes, Metabolic Syndrome and Obesity: Targets and Therapy, 7, 145-151. http://dx.doi.org/10.2147/DMSO.S60294

Zera, C., McGirr, S., \& Oken, E. (2011). Screening for Obesity in Reproductive-Aged Women. Preventing Chronic Disease, 8, A125. 